\section{Embryonic Cerebrospinal Fluid Activates Neurogenesis of Neural Precursors within the Subventricular Zone of the Adult Mouse Brain}

\author{
E. Carnicero ${ }^{a, c}$ M.I. Alonso ${ }^{a, c}$ R. Carretero $^{a}$ F. Lamus ${ }^{a} \quad$ J.A. Moro ${ }^{a, c}$ \\ A. de la Mano ${ }^{a, c} \quad$ J.M.F. Fernández ${ }^{b} \quad$ A. Gato ${ }^{a, c}$ \\ Departamentos de a Anatomía y Radiología and ' Biología Celular, Histología y Farmacología, Facultad de Medicina, \\ and ' 'Laboratorio de Desarrollo y Teratología del Sistema Nervioso, Instituto de Neurociencias de Castilla y León, \\ Universidad de Valladolid, Valladolid, Spain
}

C. S. Karger AG, Basel

\section{PROOF Copy for personal use only}

ANY DISTRIBUTION OF THIS ARTICLE WITHOUT WRITTEN CONSENT FROM S. KARGER AG, BASEL IS A VIOLATION OF THE COPYRIGHT.

\section{Key Words}

Embryonic cerebrospinal fluid - Subventricular zone ·

Neuronal precursors · Adult brain · Neurogenesis

\begin{abstract}
Introduction: There is a nondeveloped neurogenic potential in the adult mammalian brain, which could be the basis for neuroregenerative strategies. Many research efforts have been made to understand the control mechanisms which regulate the transition from a neural precursor to a neuron in the adult brain. Embryonic cerebrospinal fluid (CSF) is a complex fluid which has been shown to play a key role in neural precursor behavior during development, working as a powerful neurogenic inductor. We tested if the neurogenic properties of embryonic CSF are able to increase the neurogenic activity of neuronal precursors from the subventricular zone (SVZ) in the brains of adult mice. Results: Our results show that mouse embryonic CSF significantly increases the neurogenic activity in precursor cells from adult brain SVZ. This intense neurogenic effect was specific for embryonic CSF and was not induced by adult CSF. Conclusions: Embryonic CSF is a powerful neurogenesis inductor in homologous neuronal precursors in the adult brain. This property of embryonic CSF could be a useful tool in neuroregeneration strategies.

(c) 2013 S. Karger AG, Basel
\end{abstract}

\section{Introduction}

Neurons are generated from undifferentiated cells or neural precursors, via a complex process called 'neurogenesis' that occurs in the stages of early postnatal development. During these stages, the precursor neurons are under a very intense embryonic stimulus. However, today we have evidence that, in the adult brain of mammals in-

\begin{tabular}{|c|c|}
\hline \multicolumn{2}{|c|}{ Abbreviation used in this paper } \\
\hline CSF & cerebrospinal fluid \\
\hline SVZ & subventricular zone \\
\hline PBS & phosphate buffered saline \\
\hline BSA & bovine serum albumin \\
\hline EDTA & ethylenediaminetetraacetic acid \\
\hline PSA-NCAM & $\begin{array}{l}\text { polysialic acid neural cell adhesion } \\
\text { molecular }\end{array}$ \\
\hline DMEN & Dulbecco's modified eagle medium \\
\hline HEPES & $\begin{array}{l}\text { N-2 hydroxyethylpiperazine } \mathrm{N}-2 \\
\text { ethanesulfonic acid }\end{array}$ \\
\hline EGF & epidermal growth factor \\
\hline FGF & fibroblast growth factor \\
\hline BrdU & bromodeoxyuridine \\
\hline ANOVA & analysis of variance \\
\hline RALDH & retinaldehyde dehydrogenase \\
\hline RA & inoic acid \\
\hline
\end{tabular}

Prof. Dr. med. Ángel Gato

Department of Anatomy and Radiology, Faculty of Medicine, University of Valladolid C/ Ramón y Cajal 7

ES-47005 Valladolid (Spain)

E-Mail gato@med.uva.es 
cluding humans, there is active neurogenesis in at least two specific locations, the subventricular zone (SVZ) and the dentate gyrus of the hippocampus, which are related to the olfactory system and short-term memory circuits, respectively. It has been found that the neurogenic activity of the adult brain is less intense than during the development of the brain and that this activity also decreases with age [Merkle and Alvarez-Buylla, 2006; Arias-Carrión et al., 2007].

Adult brain neurogenesis has been considered as a potential new therapy to restore focally damaged nervous tissue as in stroke, or diffuse damage as in neurodegenerative diseases [Okano and Sawamoto, 2008; Kaneko et al., 2011]. Effective regenerative neurogenesis seems to be limited by two barriers. The first is the limited neurogenic activity in the adult mammal brain which is probably conditioned by the stem cells niche. The second is the microambient conditions in the damaged area that make changes for neuronal survival and functional integration difficult [Zhang et al., 2006; Kaneko and Sawamoto, 2009; Kernie and Parent, 2010].

There is much evidence that the adult brain neurogenic area has a greater neurogenic capacity than that which it develops in physiological conditions. This neurogenic activity depends on the microenvironmental influences conceptualized as a 'stem cells niche'. In fact, a stem cells niche, both during development and in the adult, is a microenvironment created by several cell types (including neural precursors) together with diffusible signals present in the extracellular matrix and cerebrospinal fluid (CSF) [Kazanis et al., 2008]. The composition of this set of diffusible signals and their biological significance remains largely unknown to date; however, it is clear that they evolve ontogenically, undergoing changes in their composition and properties which induces a progressive decrease in activity in the different stages of life [Lathia et al., 2007; Kazanis et al., 2008; Christie and Turnley, 2013].

We previously described a key role for CSF in early brain development [Gato and Desmond, 2009]. Embryonic CSF has been demonstrated to be a key component of the embryonic brain stem cells niche, promoting survival, replication and neurogenesis in neuroepithelial precursors [Gato et al., 2005; Alonso et al., 2011]. The embryonic CSF composition is complex [Gato et al., 2004; Parada et al., 2005; 2006] and some of its components such as FGF2, IGFI and retinol-binding-protein, have been shown to be involved in mitogenic and neurogenic activity [Martín et al., 2006; Miyan et al., 2006; Alonso et al., 2011; Zappaterra and Lehtinen, 2012]. CSF also undergoes an ontogenic evolution and the changes in its composition and biological properties could explain the changes in stem cells niche activity. In fact, adult CSF has been described as being an inductor of gliogenesis [Buddensiek et al., 2009] and also a guidance substance for cellular migration [Sawamoto et al., 2006].

On the other hand, neural precursors at different stages of life seem to be derived from the same cellular lineage as neuroepithelial cells during embryonic development, radial glia cells during the fetal and postnatal stages and specific astrocytes in the adult brain [Kriegstein and Alvarez-Buylla, 2009].

Here we test the hypothesis that neural precursors in the adult mammalian brain remain able to respond to embryonic CSF and, by doing so, increase their neurogenic activity and open the possibility of activating neuronal regeneration.

\section{Material and Methods}

Our experimental approach was based on isolation of undifferentiated neuronal precursors from the SVZ in the adult mouse brain, and then culturing them in vitro in the presence of embryonic CSF. Our isolation system was based on an immunomagnetic technique developed by magnetic-activated cell sorting, better known as the MACS ${ }^{\circledR}$ method. Briefly, embryonic CSF was obtained by microaspiration from 12.5-day-old mouse embryos (Swiss-Webster strain) as we have previously described [Gato and Desmond, 2009]. CSF was obtained from adults of both sexes at the age of 3-4 months, by micropuncture of the 'cisterna magna' according to the technique of Liu and Duff [2008].

Brains were obtained by surgery from mice under deep anesthesia. Upon removal, the brains were immediately immersed in sterile saline at $4^{\circ} \mathrm{C}$. A medial sagittal section was made, in order to obtain isolated hemispheres which were placed in $3 \%$ agar blocks and stored for $1.5 \mathrm{~h}$ at $4^{\circ} \mathrm{C}$. A vibrotome was used to obtain $400-\mu \mathrm{m}$-thick sections from the SVZ, close to the anterior horn of the lateral ventricle. Under a binocular microscope, a 2-mm-thick band of each SVZ section lining the outer wall of the lateral ventricle was excised with a microknife and was stored in an Eppendorf tube at $4^{\circ} \mathrm{C}$ (fig. 1).

SVZ tissue was disaggregated by alternating trypsin digestion, and mechanical disaggregation cycles using the Neural Tube Dissociation kit from MACS according to the manufacturer's instructions. After the elimination of undissociated tissue with a preseparation filter (of $50-\mu \mathrm{m}$ pore diameter; MACS), cells were obtained by centrifugation and resuspended in PBS-BSA-EDTA buffer at $4{ }^{\circ} \mathrm{C}$.

To isolate specific cell types, we used the strategy developed by MACS, based on specific immunolabeling of a type of cell with an antibody linked to iron particles which allows it to be retained by an intense magnetic field.

Following the manufacturer's instructions, we first isolated the glial precursors by immunolabeling with antibody A2B5 microbeads (MACS) and eluting through an MS-MACS column under an intense magnetic field, in order to retain glial precursors. The eluted cells were immunolabeled with anti-polysialic acid neural cell adhe-
2

Cells Tissues Organs

DOI: $10.1159 / 000356983$
Carnicero/Alonso/Carretero/Lamus/

Moro/de la Mano/Fernández/Gato 


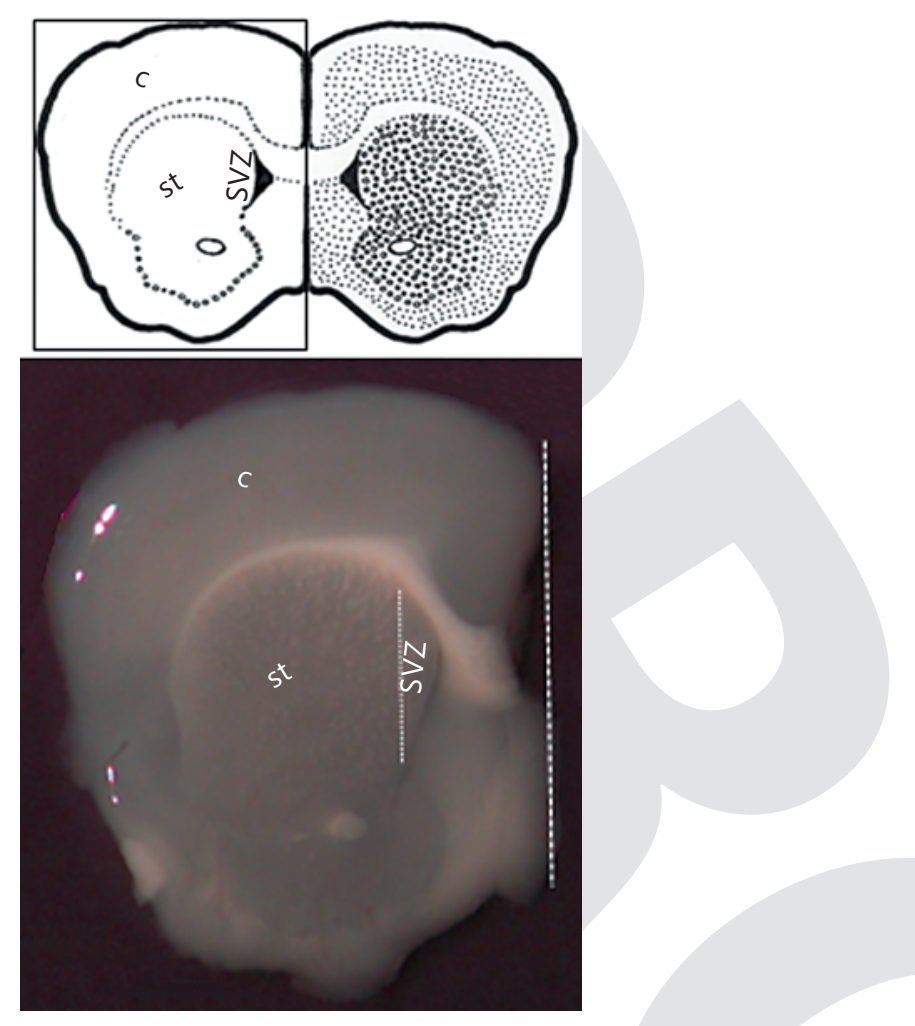

Fig. 1. Location of neural precursors in the SVZ. Mouse adult brain hemisphere section showing the cerebral cortex (c), the striatum (st) and the SVZ.

sion molecule (PSA-NCAM) antibody microbeads (MACS), specific for undifferentiated neuronal precursors and after elution through an MS-MACS column under an intense magnetic field, the rest of the cells were discarded in the eluted fraction. After eliminating the magnetic field, the undifferentiated neuronal precursors were eluted from the column ready to initiate the culture.

We developed an initial culture period of 5 days at $37^{\circ} \mathrm{C}$ and $5 \% \mathrm{CO}_{2}$ in $25-\mathrm{cm}^{2} \mathrm{TPP}^{\circledR}$ culture flasks with $5 \mathrm{ml}$ of culture medium supplemented with mitogenic growth factors (per $100 \mathrm{ml}: 85$ $\mathrm{ml} \mathrm{DMEM} / \mathrm{F} 12(1: 1)+2.4 \mathrm{ml}$ glucose $25 \%+1.5 \mathrm{ml} \mathrm{NaHCO} 37.5 \%$ $+0.5 \mathrm{ml}$ HEPES $1 \mathrm{M}+1 \mathrm{ml}$ glutamine $+10 \mathrm{ml} 10 \times$ hormone mix $+0.2 \mathrm{ml}$ heparin $0.2 \%+1 \mathrm{ml}$ penicillin/streptomycin $+20 \mathrm{ng} / \mathrm{ml}$ r-EGF (Sigma) and $10 \mathrm{ng} / \mathrm{ml}$ r-FGF-2 (Sigma). After the cells were centrifuged and resuspended in $500 \mu$ of culture medium without growth factors, the concentration of cells was calculated using a hemocytometer. Drops ( $50 \mu \mathrm{l}$ each) of culture medium containing 5,000 cells were placed on $13-\mathrm{mm}$ glass cover slides with poly-Dlysine and laminin. We made a 48-hour second period of cellular culture under the same conditions, but substituted the following for growth factors: culture medium only or $10 \%$ embryonic CSF or $10 \%$ adult CSF in the culture medium. In all cases, the culture medium contained bromodeoxyuridine (BrdU; $10 \mu \mathrm{M})$ to allow for the assessment of cellular proliferation.

After fixation in buffered $4 \%$ paraformaldehyde $(30 \mathrm{~min}$ at room temperature), a standard single or double immunolabeling

Embryonic CSF and Neurogenesis in Adult Brain procedure was developed to evaluate the degree of cellular differentiation with the following antibodies:

- Anti-BrdU: developed in mouse (Dako, ref. M7240) dilution 1/50. Secondary: anti-mouse IgG-Alexa 488 (Invitrogen, ref. 10680), dilution $1 / 1,000$.

- Anti-PSA-NCAM: developed in mouse (Chemicon, ref. MAB 5324), dilution 1/ 200. Secondary: anti-mouse IgM-Alexa 568 (Invitrogen, ref. A21043) dilution 1/1,000.

- Anti-Sox2 (D-17): developed in goat (Santa Cruz Biotechnology, ref. sc-17319) dilution 1/50. Secondary: anti-goat IgGAlexa 594 (Invitrogen, ref. A110 58), dilution 1/1,000.

- Anti-III- $\beta$-tubulin: developed in rabbit (Sigma, ref. T2200), dilution 1/20. Secondary: anti-rabbit IgG-Alexa 488 (Invitrogen, ref. A11008) dilution 1/1,000.

Immunolabeling was visualized with a Leica TCS SPE confocal laser microscope. At least 20 images with the same magnification were made from each experimental condition, from 5 different cultures and we randomly chose 20 areas of $0.0269 \mathrm{~mm}^{2}$ to count positive cells $(n=20)$. The data were analyzed by ANOVA.

\section{Results}

In order to test the efficiency after our procedure to select neural precursors based on PSA-NCAM immunoselection, we took a small amount of cells isolated from the SVZ and immunolabeled them with PSA-NCAM antibody. Almost every cell from the isolation procedure showed a positive inmunolabeling, so that we started our culture with a homogeneous population of undifferentiated neuronal precursor cells from the SVZ in the brains of adult mice.

The number of precursor cells isolated from the SVZ was not very high; consequently, we performed an initial expansive phase of culture (for 5 days) under the influence of FGF2 and EGF, two well-known, mitogenic factors for this type of cell [Panchision and McKay, 2002]. The mean number of cells by area was 5.75 at the beginning of the expansive phase of the culture and it increased to 36.3 after 5 days, a $531 \%$ increase. To test the undifferentiated stage of the expanded neuronal precursor population in expansive cultures, we developed a double inmunolabeling with BrdU antibody (a proliferative marker for precursor cells) together with anti-Sox 2 antibody (a marker of undifferentiated neural precursors [Sawada and Sawamoto, 2013]. As shown in figure 2, nearly $90 \%$ of the cells, after the expansive period, showed a double labeling for BrdU and Sox 2 and only $10 \%$ showed only BrdU labeling. These data reveal that we mainly isolated a population of undifferentiated neuronal precursors at the beginning of our experimental study.

We studied the trophic effect of embryonic CSF upon undifferentiated adult brain neural precursors in mice, by

Cells Tissues Organs

DOI: $10.1159 / 000356983$ 


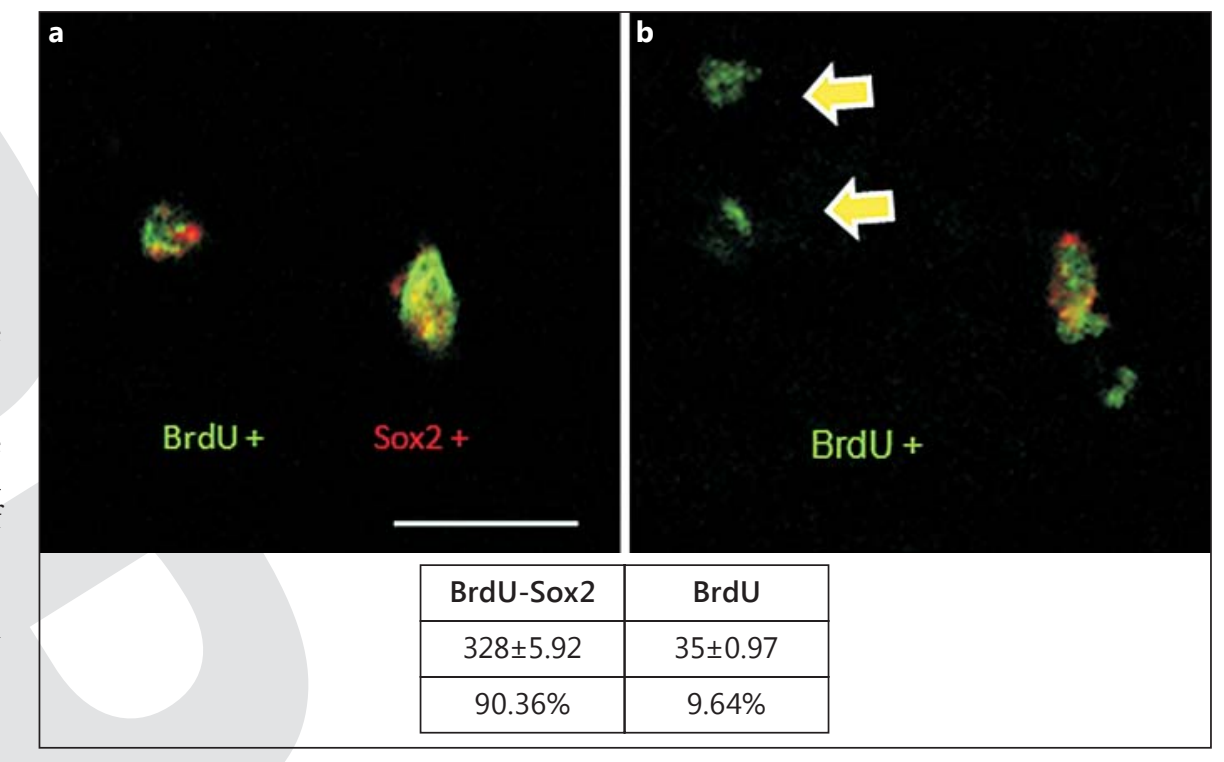

Fig. 2. Undifferentiated state of cell culture after the expansion period. Double inmunolabeling with BdrU (green) and Sox2 antibody (red) of SVZ precursor cells after the expansive phase of in vitro culture. Data show a main $(90.36 \%)$ cell population of 'undifferentiated neuronal precursor cells' which expressed both antigens (a), together with a minor $(9.64 \%)$ cell population which expressed only BrdU antigen (b: arrows) at the start of the experimental culture. Scale bar: $10 \mu \mathrm{m}$.

48-hour culture of the expanded population of neural precursors in defined culture medium containing $10 \%$ embryonic CSF, $10 \%$ adult CSF or only defined culture medium.

We added BrdU to the culture medium in the expansion period, so all of the cells showed a BrdU-positive nucleus (confirming their neural precursor origin). On the other hand, the early neuronal commitment was detected by the progressive expression of $\beta 3$-tubulin in the cytoplasm.

In order to evaluate the neurogenic inductive power of the embryonic CSF, we evaluated three different types of cells at the end of the experimental culture: cells that expressed only BrdU in the nucleus (undifferentiated neuronal precursors), cells which coexpressed $\mathrm{BrdU}$ in the nucleus combined with a low expression of $\beta 3$-tubulin in the cytoplasm (only newborn neurons) and cells which coexpressed BrdU in the nucleus combined with an intense expression of $\beta 3$-tubulin (young neurons) in the cytoplasm (see fig. $3 \mathrm{a}-\mathrm{c}$ ). As is shown in figure $3 \mathrm{~d}$, the presence of embryonic CSF does not modify the number of BrdU-positive cells or BrdU-positive cells when there is a low coexpression of $\beta 3$-tubulin cells with respect to the negative controls (i.e. defined medium only). However, when there was an intense coexpression of $\beta 3$-tubulin in the cytoplasm, we found an intense (i.e. 38\%) and statistically significant increase in the number of cells with a BrdU-positive nucleus compared to the negative controls. These data show that embryonic CSF is able to significantly activate the neurogenesis in the neural precur- sors from the adult brain, increasing not only the number of neurons but also the speed of neuron maturation.

In order to assess the specificity of the neurogenic effect induced by the embryonic CSF, we performed a complementary positive control with the addition of $10 \%$ CSF from adult mice. As shown in figure 3, the adult CSF was able to maintain a similar number of BrdU-positive cells in culture, but it was unable to increase the number of $\beta 3$ tubulin-positive cells (both with lesser or greater $\beta 3$ tubulin expression), even falling beneath the control values. These data support our idea that the intense neurogenesis induction was a specific property of embryonic CSF.

\section{Discussion}

Embryonic CSF Activates Neurogenesis of

Undifferentiated Neuronal Precursors in the Adult Mouse Brain

Our results show that embryonic CSF exerts a specific influence over an undifferentiated neuronal precursor population from the SVZ in the adult mouse brain. The main effect detected in our study was an activation of the transition from undifferentiated neuronal precursors to young neurons, i.e. the induction of neurogenesis. Despite the fact that our data do not show a significant effect of embryonic CSF on cellular replication, we cannot rule out this possibility because we started our experimental culture just after a period of expansion culture in which
4

Cells Tissues Organs

DOI: $10.1159 / 000356983$
Carnicero/Alonso/Carretero/Lamus/

Moro/de la Mano/Fernández/Gato 

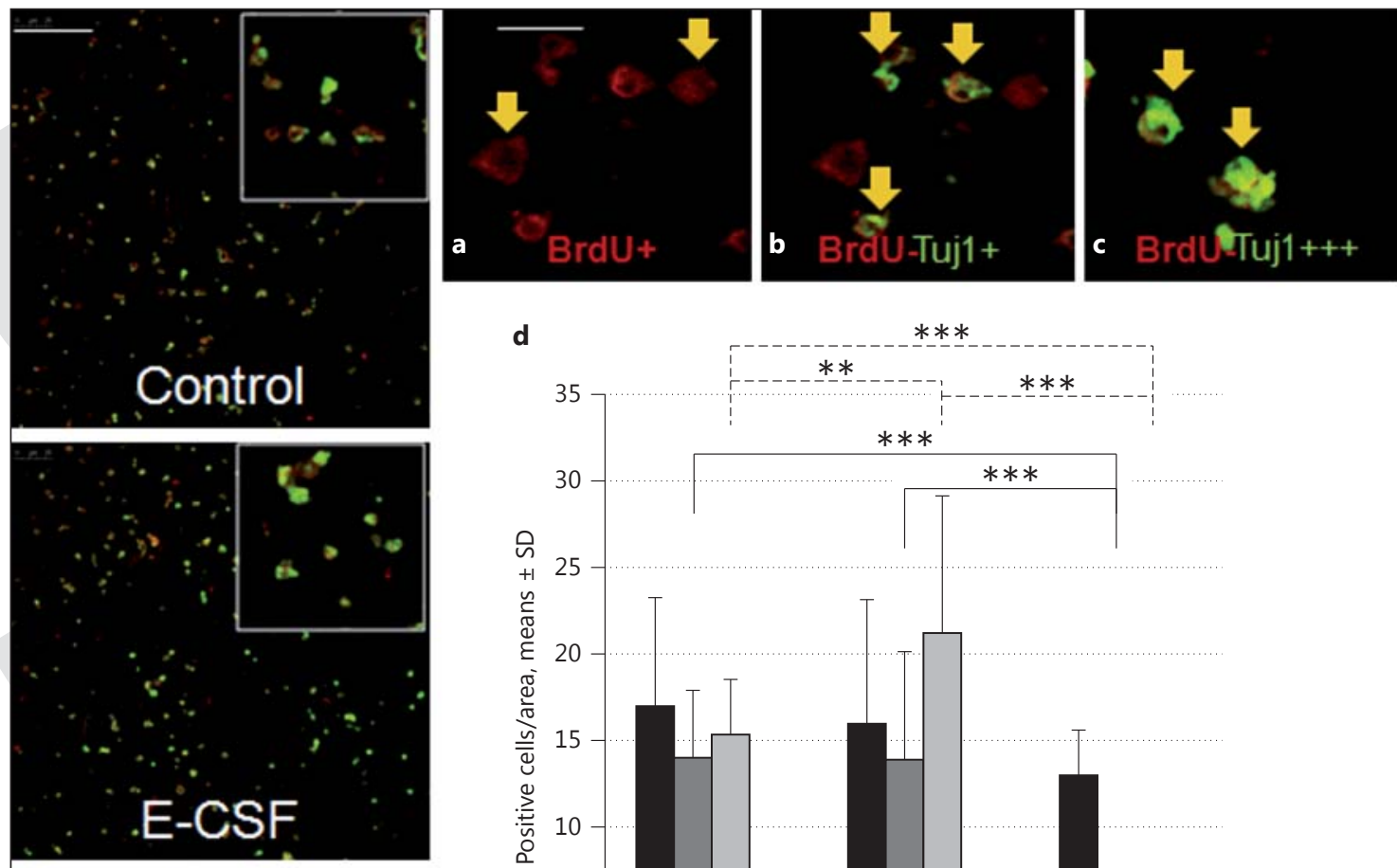

\section{d}
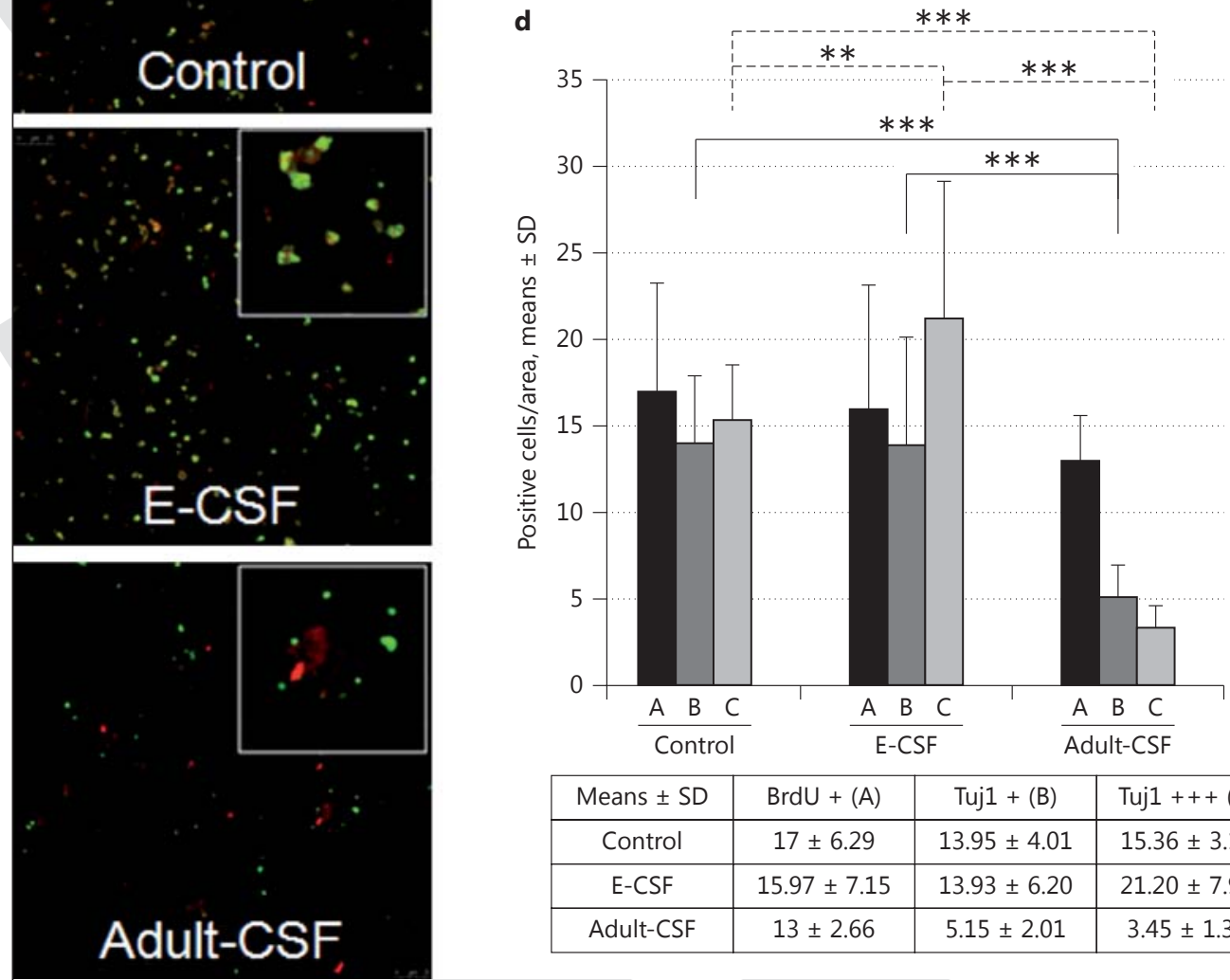

\begin{tabular}{|c|c|c|c|}
\hline Means \pm SD & BrdU $+(\mathrm{A})$ & Tuj1 $+(\mathrm{B})$ & Tuj1 +++ (C) \\
\hline Control & $17 \pm 6.29$ & $13.95 \pm 4.01$ & $15.36 \pm 3.19$ \\
\hline E-CSF & $15.97 \pm 7.15$ & $13.93 \pm 6.20$ & $21.20 \pm 7.97$ \\
\hline Adult-CSF & $13 \pm 2.66$ & $5.15 \pm 2.01$ & $3.45 \pm 1.32$ \\
\hline
\end{tabular}

Fig. 3. Embryonic CSF induces neurogenesis. Double inmunolabeling with BdrU (red) and $\beta$-tubulin (Tuj1) (green) antibody specific for young neurons, after the experimental phase of SVZ precursors in in vitro culture. Upper images show the three types of quantified cells. a $\mathrm{BdrU}(+)$-Tuj1(-). b $\mathrm{BdrU}(+)-\mathrm{Tuj} 1(+)$. c BdrU(+)-Tuj1(+++). Scale bar: $10 \mu \mathrm{m}$. The images and their in-

neuronal precursors had been under the effect of intense mitogenic growth factors such as FGF2 and EGF which could have hidden a possible mitogenic effect.

The ability of embryonic CSF to induce neurogenesis has been demonstrated previously in the early brain development of chick [Gato et al., 2005] and rat embryos [Martín et al., 2009]. There are several studies which attribute the neurogenic properties of embryonic CSF to particular components of this fluid such as retinol-binding protein and retinol [Parada et al., 2008b; Alonso et al., 2011] or lipoproteins [Parada et al., 2008a], which, with

Embryonic CSF and Neurogenesis in Adult Brain sets on the left side represent each experimental condition. E-CSF = Embryonic CSF. Scale bar: $50 \mu \mathrm{m}$. d The data about the different types of cultivated cells in each experimental condition were plotted in the bar graphs together with the statistical significance measured by a one-way ANOVA, post hoc Bonferroni test $(\mathrm{n}=20){ }^{* * *} \mathrm{p}<0.001,{ }^{* *} \mathrm{p}<0.05$.

the concurrence of RALDH activity, have been involved in the synthesis of retinoic acid (RA). This well-known morphogen is directly linked to the neural differentiation and patterning of anterior-posterior and dorsoventral axes in brain development [McCaffery and Dräger, 2000; Diez del Corral and Storey, 2001; McCaffery et al., 2003]. Taking into account that the presence of enzymatic elements necessary for RA synthesis was described in the choroid plexus and also in the SVZ of the adult brain, and that a direct relationship between RA and neurogenesis in this area has been described [Haskell and La Mantia,

Cells Tissues Organs

DOI: $10.1159 / 000356983$ 
2005; Wang and Liu, 2005; McCaffery, 2006; Zhang et al., 2006], we can hypothesize that embryonic CSF neurogenic induction in adult brain precursor cells could be mediated by the influence of RA synthesis regulation. However, neurogenesis regulation is a complex process in which several regulatory molecules appear to be involved [Panchision and McKay, 2002; Lehtinen and Walsh, 2011].

\section{CSF Acts as a Key Component of the Neuronal} Precursors 'Niche'

Our results clearly support the hypothesis that CSF is a component of the cell regulatory microenvironment of brain precursors which respond to the 'niche' concept. Much of the recent research supports the existence of a complex microenvironment at the two sites of adult brain neurogenesis, the SVZ and the dentate gyrus, which include several cell types like neurons, precursors, glia and vascular cells. These cells form a 3-dimensional structure [Merkle and Alvarez-Buylla, 2006], with many different intracellular and intercellular signals which are still not completely understood, despite the fact that several growth factors, cytokines and other molecules have been described to date [Lathia et al., 2007; Kazanis et al., 2008; Zappaterra and Lehtinen, 2012]. This complex microenvironment has been proposed as being responsible for the activity of neural precursors, both during development and in adult life.

It appears to be a constant that the precursor cells are in contact with the CSF inside the brain cavities, i.e. from the embryonic stage to the adult stage, and this interface has been proposed as a key factor in the regulation of precursor cell behavior [Gato and Desmond, 2009; Kriegstein and Alvarez-Buylla, 2009; Lehtinen and Walsh, 2011; Zappaterra and Lehtinen, 2012]. In fact, CSF was included as a specific component of the adult mouse SVZ niche [Lathia et al., 2007; Ihrie and Alvarez-Buylla, 2011] which has to be taken into account in order be able to understand the process of neurogenesis.

Our results show that adult brain precursor cells are able to respond to the influence of embryonic CSF in the same way as neuroepithelial cells, i.e. by increasing neurogenesis. Previous studies from Buddensiek et al. [2009] showed that adult CSF induces mainly gliogenesis in the neuronal precursors from the adult human hippocampus. This is in agreement with our results which showed a very low neurogenic response of SVZ neuronal precursors to adult mouse CSF. Both data support the idea; it was previously described [Miyan et al., 2006; Kazanis et al., 2008; Zappaterra and Lehtinen,
2012] that CSF composition evolves ontogenically, becoming less active in the neurogenic induction. This can justify, at least in part, the restriction of neuroregeneration with age.

\section{Ontogenesis of Brain Neural Precursors: A Unique Cell Lineage}

The origin of the brain neural stem cell has been the object of several hypotheses, particularly after the discovery of the astrocytic characteristics of adult brain neural precursors both in the SVZ and hippocampal dentate gyrus [Kriegstein and Alvarez-Buylla, 2009]. Although some studies proposed a glial (astrocites) redifferentiation to newborn neurons, there are several others which proposed a common or continuous cellular lineage of neural precursors throughout a person's life, which includes neuroepithelial cells in the embryonic stage, radial glia at the fetal stage and specific astrocites during adult life [Ihrie and Alvarez-Buylla, 2011; Kuhn and Blomgren, 2011].

Our results show that the adult neuronal precursors are able to respond in the same way as embryonic neuroepithelial cells to an embryonic stimulus such as CSF [Gato et al., 2005; Martín et al., 2009]. This ability supports the theory that, in the course of a lifetime, neural precursor cells come from the same cellular type.

\section{Conclusions}

Based on our data, we conclude that a physiological way to increase neurogenesis in the adult mammalian brain comes from the use of an embryonic neurogenic stimulus like CSF. This property of CSF could be a useful tool for inducing neuroregeneration in the adult brain.

\section{Acknowledgements}

The authors thank Prof. Dr. Mary Desmond for the helpful critical revision of the manuscript and the Ministerio de Educación y Ciencia (BFU207/6516) and Junta de Castilla y León (Consejería de educación, GR195) for their financial support of the research team.

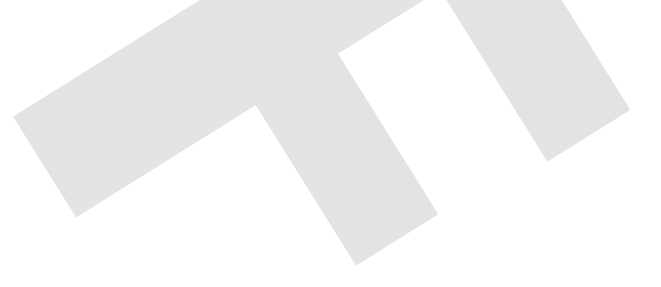




\section{References}

Alonso, M.I., C. Martin, E. Carnicero, D. Bueno, A. Gato (2011) Cerebrospinal fluid control of neurogenesis induced by retinoic acid during early brain development. Dev Dyn 240: 16501659.

Arias-Carríon, O., T. Olivares-Banuelos, R. Drucker-Colin (2007) Neurogenesis in the adult brain. Revist Neurol 44: 541-550.

Buddensiek, J., A. Dressel, M. Kowalski, A. Storch, M. Sabolek (2009) Adult cerebrospinal fluid inhibits neurogenesis but facilitates gliogenesis from fetal rat neural stem cells. J Neurosci Res 87: 3054-3066.

Christie, K., A.M. Turnley (2013) Regulation of endogenous neural stem/progenitor cells for neural repair-factors that promote neurogenesis and gliogenesis in the normal and damaged brain. Front Cell Neurosci 6: 70

Diez del Corral, R., K.G. Storey (2001) Markers in vertebrate neurogenesis. Nat Rev Neurosci 2 835-839.

Gato, A., M.E. Desmond (2009) Why the embryo still matters: CSF and the neuroepithelium as interdependent regulators of embryonic brain growth, morphogenesis and histiogenesis. Dev Biol 327: 263-272.

Gato, A., P. Martin, M.I. Alonso, C. Martin, M.A Pulgar, J.A. Moro (2004) Analysis of cerebrospinal fluid protein composition in early developmental stages in chick embryos. J Exp Zool A Comp Exp Biol 301A: 280-289.

Gato, A., J.A. Moro, M.I. Alonso, D. Bueno, A. De la Mano, C. Martin (2005) Embryonic cerebrospinal fluid regulates neuroepithelial survival, proliferation, and neurogenesis in chick embryos. Anat Rec A Discov Mol Cell Evol Biol 284A: 475-484.

Haskell, G.T., A.S. La Mantia (2005) Retinoic acid signaling identifies a distinct precursor population in the developing and adult forebrain J. Neurosci 25: 7636-7647.

Ihrie, R.A., A. Alvarez-Buylla (2011) Lake-front property: a unique germinal niche by the lateral ventricles of the adult brain. Neuron 70 : 674-686.

Kaneko N., E. Kako, K. Sawamoto (2011) Prospects and limitations of using endogenous neural stem cells for brain regeneration. Genes 2: 107-130.

Kaneko, N., K. Sawamoto (2009) Adult neurogenesis and its alteration under pathological conditions. Neurosci Res 63: 155-164.
Kazanis, I., J. Lathia, L. Moss, C. ffrench-Constant (2008) The neural stem cell microenvironment; in Scadden, D. (ed): StemBook. Cambridge, Mass., Stem Cell Research Community.

Kernie, S.G., J.M. Parent (2010) Forebrain neurogenesis after focal ischemic and traumatic brain injury. Neurobiol Dis 37: 267-274

Kriegstein, A., A. Alvarez-Buylla (2009) The glial nature of embryonic and adult neural stem cells. Annu Rev Neurosci 32: 149-184.

Kuhn, H.G., K. Blomgren (2011) Developmental dysregulation of adult neurogenesis. Eur J Neurosci 33: 1115-1122.

Lathia, J.D., M.S. Rao, M.P. Mattson, C. FfrenchConstant (2007) The microenvironment of the embryonic neural stem cell: lessons from adult niches? Dev Dyn 236: 3267-3282.

Lehtinen, M.K., C.A. Walsh (2011) Neurogenesis at the brain-cerebrospinal fluid interface. Annu Rev Cell Dev Biol 27: 653-679.

Liu, L., K. Duff (2008) A technique for serial collection of cerebrospinal fluid from the cisterna magna in mouse. J Vis Exp DOI: 960.10.3791/960

Martín, C., M.I. Alonso, C. Santiago, J.A. Moro, A. De la Mano, R. Carretero, A. Gato (2009) Early embryonic brain development in rats requires the trophic influence of cerebrospinal fluid. Int J Dev Neurosci 27: 733-740.

Martín, C., D. Bueno, M.I. Alonso, J.A. Moro, S. Callejo, C. Parada, P. Martin, E. Carnicero, A Gato (2006) FGF2 plays a key role in embryonic cerebrospinal fluid trophic properties over chick embryo neuroepithelial stem cells. Dev Biol 297: 402-416.

McCaffery, P. (2006) Retinoic acid regulates neurogenesis in the hippocampus - possible consequences for depression. Int J Neuropsychopharmacol 9: S79-S80.

McCaffery, P.J., J. Adams, M. Maden, E. RosaMolinar (2003) Too much of a good thing: retinoic acid as an endogenous regulator of neural differentiation and exogenous teratogen. Eur J Neurosci 18: 457-472.

McCaffery, P., U.C. Dräger (2000) Regulation of retinoic acid signaling in the embryonic nervous system: a master differentiation factor. Cytokine Growth Factor Rev 11: 233-249.

Merkle, F.T., A. Alvarez-Buylla (2006) Neural stem cells in mammalian development. Curr Opin Cell Biol 18: 704-709.
Miyan, J.A., M. Zendah, F. Mashayekhi, P.J. Owen-Lynch (2006) Cerebrospinal fluid supports viability and proliferation of cortical cells in vitro, mirroring in vivo development. Cerebrospinal Fluid Res 3: 2.

Okano, H., K. Sawamoto (2008) Neural stem cells: involvement in adult neurogenesis and CNS repair. Philos Trans R Soc Lond B Biol Sci 363: 2111-2122.

Panchision, D.M., R.D.G. McKay (2002) The control of neural stem cells by morphogenic signals. Curr Opin Genet Dev 12: 478-487.

Parada, C., J. Carles Escola-Gil, D. Bueno (2008a) Low-density lipoproteins from embryonic cerebrospinal fluid are required for neural differentiation. J Neurosci Res 86: 2674-2684

Parada, C., A. Gato, M. Aparicio, D. Bueno (2006) Proteome analysis of chick embryonic cerebrospinal fluid. Proteomics 6: 312-320.

Parada, C., A. Gato, D. Bueno (2005) Mammalian embryonic cerebrospinal fluid proteome has greater apolipoprotein and enzyme pattern complexity than the avian proteome. J Proteome Res 4: 2420-2428.

Parada, C., A. Gato, D. Bueno (2008b) All-trans retinol and retinol-binding protein from embryonic cerebrospinal fluid exhibit dynamic behaviour during early central nervous system development. Neuroreport 19: 945-950.

Sawada, M., K. Sawamoto (2013) Mechanisms of neurogenesis in the normal and injured adult brain. Keio J Med 62: 13-28.

Sawamoto, K., H. Wichterle, O. Gonzalez-Perez, J.A. Cholfin, M. Yamada, N. Spassky, N.S. Murcia, J.M. Garcia-Verdugo, O. Marin, J.L.R. Rubenstein, M. Tessier-Lavigne, H. Okano, A. Alvarez-Buylla (2006) New neurons follow the flow of cerebrospinal fluid in the adult brain. Science 311: 629-632.

Wang, H.F., F.C. Liu (2005) Regulation of multiple dopamine signal transduction molecules by retinoids in the developing striatum. Neuroscience 134: 97-105.

Zappaterra, M.W., M.K. Lehtinen (2012) The cerebrospinal fluid: regulator of neurogenesis, behavior, and beyond. Cell Mol Life Sci 69: 2863-2878

Zhang, X.D., K.M. Klueber, Z.F. Guo, J. Cai, C.L Lu, W.I. Winstead, M.S. Qiu, F.J. Roisen (2006) Induction of neuronal differentiation of adult human olfactory neuroepithelial-derived progenitors. Brain Res 1073: 109-119. 